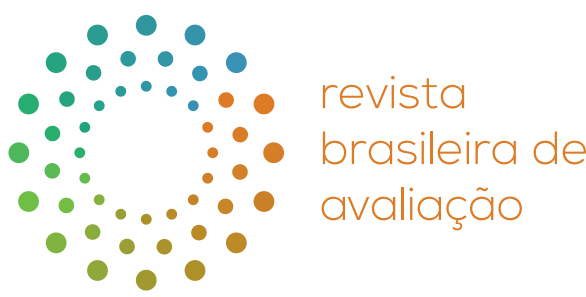

\title{
Atuação anticorrupção e avaliação de políticas públicas: uma relação possível?
}

\author{
Special Operations and Public Policy Evaluation - is this a possible \\ relashionship?
}

Patricia Alvares de Azevedo Oliveira ${ }^{1,2 *}$ [Branca] (D)

${ }^{1}$ Controladoria Geral da União (CGU), Brasília, DF, Brasil

${ }^{2}$ Escola Nacional de Administração Pública (ENAP), Brasília, DF, Brasil

COMO CITAR: Oliveira, Patricia Alvares de Azevedo (2021). Atuação anticorrupção e avaliação de políticas públicas: uma relação possível?. Revista Brasileira de Avaliação, 10(1), 100421. https://doi.org/10.4322/rbaval202110004

\section{Resumo}

Nas Operações Especiais, a Controladoria-Geral da União (CGU), em parceria com órgãos como a Polícia Federal e o Ministério Público Federal, investiga a malversação de recursos públicos descentralizados para execução de políticas públicas federais. Trabalhos acadêmicos foram produzidos para analisar os resultados do Programa de Fiscalização por Sorteios Públicos e seu impacto na qualidade da gestão pública, na inibição de práticas de corrupção e até mesmo na reeleição de candidatos a prefeitos; mas uma possível relação da atividade de Operações Especiais com a avaliação de políticas públicas ainda não foi explorada academicamente. Utilizando-se de abordagem qualitativa, por meio de pesquisa exploratória, foi identificada a trajetória dessa atividade nos últimos 17 anos e os principais resultados relatados pela CGU. A proposta deste ensaio é debater possíveis formas de aproveitamento dos resultados dessas ações como subsídio à avaliação de desenho e avaliação da governança, a partir do conhecimento das causas que possibilitaram a ocorrência dos ilícitos.

Palavras chave: Operações especiais. Avaliação de políticas públicas. Corrupção.

\begin{abstract}
In Special Operations, The Comptroller General of the Union (CGU), in partnership with agencies such as the Federal Police and the Federal Public Ministry, investigates the misuse of decentralized public resources for the implementation of federal public policies. Academic works were produced to analyze the Inspection Program by Public Draws' results and its impact on the quality of public management, in the inhibition of corrupt practices and even in the reelection of candidates for mayors; but a possible relationship between the Special Operations activity and the evaluation of public policies has not yet been explored academically. Using a qualitative approach, through exploratory research, the trajectory of this activity in the last 17 years and the main results reported by CGU were identified. The purpose of this essay is to discuss possible ways to take advantage of the results of these actions as a basis for drawing evaluation and governance evaluation, based on the knowledge of the causes that enabled the occurrence of illicit acts.
\end{abstract}

Keywords: Special operations. Evaluation of public policies. Corruption.
Recebido: Outubro 20, 2020 Aceito: Dezembro 09, 2020

*Autor correspondente: Patricia Alvares de Azevedo Oliveira E-mail: patricia.mithus@terra.com.br

\section{(cc) BY}

Este é um artigo publicado em acesso aberto (Open Access) sob a licença Creative Commons Attribution, que permite uso, distribuição e reprodução em qualquer meio, sem restrições desde que o trabalho original seja corretamente citado. 


\section{Introdução}

Conforme mandamento constitucional explicitado no art. 74, os Poderes Legislativo, Executivo e Judiciário devem manter sistemas de controle interno, com a finalidade de, dentre outras questões, avaliar a execução dos programas de governo (Brasil, 1988). No caso do Poder Executivo Federal, cabe à Controladoria-Geral da União (CGU) exercer o papel de órgão central do Sistema de Controle Interno do Poder Executivo federal (SCI) (Brasil, 2002).

Constituída com estrutura permanente e status de ministério em 2002, a CGU iniciou sua trajetória como órgão pertencente à Presidência da República, e suas funções se restringiam às atividades de auditoria pública, corregedoria e ouvidoria. O normativo que balizava as atividades de auditoria, até hoje realizadas pela Secretaria Federal de Controle Interno (SFC), identificava como uma das suas atividades essenciais a avaliação da execução dos programas de governo, ressaltando que o objetivo dessa atividade era buscar melhor alocação de seus recursos, corrigindo os desperdícios, a improbidade, a negligência e a omissão, mas também buscando garantir os resultados pretendidos (SFC, 2001).

O conceito de Controle Interno vem sendo expandido ao longo dos 18 anos de existência da CGU, partindo de um modelo estrito, no qual a atuação do Controle Interno se relacionava apenas à fiscalização contábil, financeira, orçamentária e patrimonial da União; para um modelo ampliado, que abarca capacidade de responsabilização por cometimento de irregularidades, promoção da transparência e valorização da temática de integridade pública, além do combate à corrupção (Rosário et al., 2020).

Ainda que desde o início de sua instituição já existisse a referência à luta contra a improbidade, a temática de prevenção e combate à corrupção não estava explicitada na estrutura do órgão ou nos normativos que regulamentavam as suas atividades.

Em 2003, a CGU criou o Programa de Fiscalização por Sorteios Públicos, cujo principal objetivo era verificar de que forma os recursos federais descentralizados para a execução dos programas de governo estavam sendo aplicados pelos municípios. O aumento da descentralização das políticas públicas ocorrida a partir dos anos 1980, especialmente para implementação das políticas sociais pelos municípios, justificou o esforço institucional da CGU no sentido de ampliar as fiscalizações para municípios, quando se tratava de aplicação de recursos federais (Loureiro et al., 2012).

Como objetivo secundário, o Programa pretendia "combater a prática de corrupção entre os gestores da administração pública federal" (Sodré \& Ramos, 2018, p.7). Os municípios que seriam fiscalizados eram selecionados de forma randômica, utilizando a estrutura de loteria da Caixa Econômica Federal. Equipes da CGU visitavam os municípios para verificar in loco a aplicação dos recursos federais descentralizados, e os resultados eram encaminhados aos ministérios setoriais responsáveis pelas políticas públicas, e a órgãos como os Ministérios Públicos estaduais e federal, além de amplamente divulgados na imprensa (Ferraz \& Finan, 2008).

Por doze anos, a sistemática do sorteio para seleção dos municípios a serem fiscalizados permaneceu como única opção. A partir de 2015, a iniciativa denominada Programa de Fiscalização em Entes Federativos incorporou ao Programa de Fiscalização por Sorteios Públicos outras formas de seleção (CGU, 2020a)

As mudanças na atuação da CGU continuaram a ocorrer de forma incremental. Em 2006, o órgão passou a contar com uma nova estrutura, que trouxe explicitamente para os normativos que regiam sua atuação a temática da corrupção, ainda com viés preventivo. $\mathrm{A}$ criação da Secretaria de Prevenção da Corrupção e Informações Estratégicas (SPCI) inseriu o órgão no debate internacional como agência anticorrupção brasileira, com competências para promover políticas de transparência e de fortalecimento da integridade pública como formas de combater a corrupção.

A relevância que a temática da corrupção vem ganhando no cenário nacional, especialmente a partir de 2013, refletiu na forma como a CGU passou a exercer o papel de órgão central do SCI. 
Nas atividades de auditoria realizadas pela SFC, a mudança derivou no novo formato do Programa de Fiscalização por Sorteios Públicos, rebatizado de Programa de Fiscalização em Entes Federativos, que incluiu novas formas de seleção dos municípios - censo, matriz de vulnerabilidade e sorteios, de forma alternada (CGU, 2020a).

A experiência adquirida na realização do Programa de Fiscalização por Sorteios Públicos subsidiou a decisão de adoção de matriz de vulnerabilidade para seleção de municípios a serem fiscalizados no novo Programa de Fiscalização em Entes Federativos, ainda que a opção pela modalidade via sorteio tenha permanecido. Nesse novo modelo, municípios com menores índices de transparência e controle, além de menor desenvolvimento econômico-social, pontuaram mais, indicando que a CGU considera que fragilidades em requisitos de integridade aumentam a probabilidade de utilização inadequada de recursos públicos (CGU, 2020a).

Em todos os formatos, quando surgem indícios de malversação dos recursos públicos a partir das fiscalizações, os processos subsidiam apurações em um processo denominado pela CGU como Operação Especial, o qual conta com a participação de outros órgãos federais, como o Departamento de Polícia Federal (DPF) e o Ministério Público Federal (MPF), dentre outros.

Nas Operações Especiais, a CGU entra com a expertise em auditorias para avaliar a documentação apreendida que sugere fraude à utilização de recursos federais e os órgãos parceiros entram com competências específicas, tais como realização de inquéritos policiais por parte do DPF, e representações de medidas cautelares para busca e apreensão, afastamento de sigilo bancário ou fiscal e interceptação telemática, por parte do MPF (Straus, 2020).

Grande parte das operações realizadas têm origem em atividades regulares de auditoria, algumas delas decorrentes das fiscalizações nos municípios. Não há previsão, no entanto, de retroalimentação do processo de avaliação de políticas públicas. Distintamente do ocorrido com o Programa de Fiscalização em Entes Federativos, os resultados das operações especiais não são endereçados aos ministérios setoriais e não há rotina de disponibilização dos resultados às coordenações-gerais da CGU responsáveis pelas avaliações de políticas públicas.

As mudanças políticas na Presidência e o fortalecimento da pauta do combate à corrupção por parte do governo promoveram uma nova mudança na estrutura da CGU a partir de 2019. Uma nova unidade organizacional, denominada Secretaria de Combate à Corrupção, passou a agregar as funções existentes de informações estratégicas e de realização de acordos de leniência, que estavam diretamente ligadas à Secretaria Executiva da CGU, e a atividade de Operações Especiais saiu da estrutura da SFC e ganhou status de Diretoria.

Se a sinergia entre os resultados das Operações Especiais e a avaliação de políticas públicas já era pouco significante quando esta atividade era realizada no âmbito da SFC, com a mudança para a nova estrutura, ela ficou ainda mais reduzida.

Nesse sentido, a proposta deste ensaio é instigar o debate sobre a possibilidade de que os produtos das operações retroalimentem o processo de avaliação de políticas públicas realizado pelo órgão.

Diversos trabalhos acadêmicos foram produzidos para analisar os resultados das fiscalizações por meio do sorteio e seu impacto na qualidade da gestão pública, na inibição de práticas de corrupção e até mesmo na reeleição de candidatos a prefeitos; mas uma possível relação da atividade de Operações Especiais com a avaliação de políticas públicas ainda não foi explorada academicamente.

Tendo começado em 2003 com apenas uma Operação Especial, até o início do mês de outubro de 2020 a CGU contabilizava 480 ações investigativas, com prejuízo total apurado em torno de $\mathrm{R} \$ 5,3$ bilhões. Somente em 2020, até o mês de outubro, foram realizadas sessenta e duas operações especiais, sendo a maior parte delas para apurar denúncias de fraudes relativas às compras derivadas do COVID-19 (CGU, 2020b). Esse número supera em cerca de $14 \%$ a média de operações realizadas entre 2016 e 2019, e em 320\% o realizado entre 2003 e 2015.

Este ensaio está organizado em três seções, além desta introdução e das considerações finais. A segunda seção tratará da metodologia utilizada, explicando de que forma a pesquisa foi conduzida. A terceira seção apresenta de que forma as Operações Especiais se integram na 
estrutura organizacional da CGU desde a instituição do órgão, a evolução do quantitativo de ações investigativas ao longo do período e quais as principais áreas de políticas nas quais foram realizadas. A quarta seção traz a discussão sobre possíveis formas de aproveitamento dos resultados das Operações Especiais para subsidiar o processo de avaliação de políticas públicas. Nas considerações finais são elencados alguns desafios para o avanço desse debate e sugestões de pesquisas que podem aprofundar o tema.

\section{Metodologia}

Considerando o objetivo do ensaio, a escolha metodológica recaiu sobre a abordagem qualitativa, baseada na análise de documentos formais e de dados disponibilizados no sítio eletrônico da CGU e do atual Ministério da Economia.

De forma exploratória, foi identificada a estrutura organizacional à qual pertenceu a atividade de Operações Especiais desde 2003 até o momento atual, bem como os quantitativos de ações realizadas por ano e por área de política pública investigada, quando foi a possível a identificação, e os recursos públicos envolvidos nas fiscalizações.

Na sequência, foi analisada a evolução do status organizacional da atividade e as principais políticas públicas desenvolvidas pelas pastas ministeriais cujas ações foram fiscalizadas no âmbito das Operações Especiais. Abordagens de avaliações de políticas públicas foram trazidas para o ensaio com o objetivo de se identificar com qual abordagem a atividade de Operações Especiais mais poderia contribuir com os resultados das políticas públicas.

Foram encontradas limitações à avaliação dos dados quantitativos, já que, ainda que a CGU registre a realização de 480 Operações Especiais desde a criação do órgão (CGU, 2020b), dados abertos sobre as ações investigativas encontram-se disponibilizados apenas a partir de 2016, com informações insuficientes para uma análise quantitativa dos valores envolvidos por programa de governo ou área temática.

\section{Operações especiais - Ascensão e Evolução}

Apesar de não haver a remissão ao nome Operação Especial, a Lei nº. 10.180/2001 conferiu aos órgãos pertencentes ao Sistema de Controle Interno do Poder Executivo Federal (SCI) a competência para

apurar os atos ou fatos inquinados de ilegais ou irregulares, praticados por agentes públicos ou privados, na utilização de recursos públicos federais e, quando for o caso, comunicar à unidade responsável pela contabilidade para as providências cabíveis (Brasil, 2001).

Instituída por meio do Decreto n.4.490, de 28 de novembro de 2002, com o nome de CorregedoriaGeral da União, e rebatizada Controladoria-Geral da União por meio do Decreto $n^{\circ}$. 4785, de 21 de julho de 2003, a CGU integrava a estrutura da Presidência da República, mas já tinha status ministerial, sendo dirigida pelo então Ministro de Estado do Controle e da Transparência.

De sua estrutura fazia parte a Secretaria Federal de Controle Interno (SFC), oriunda do Ministério da Fazenda, que contava com cinco diretorias de auditorias, separadas por área temática (econômica, social, infraestrutura, administração e pessoal) e uma diretoria de planejamento estratégico e avaliação das ações de controle.

Ainda que o decreto previsse a atividade de "apurar os atos ou fatos inquinados de ilegalidade ou irregularidade, praticados por agentes públicos ou privados, na utilização de recursos públicos federais" (Brasil, 2003), não havia registro de qualquer menção à atividade de Operação Especial, nem cargo designado para coordenação dessa atividade. O que mais se assemelhava à essa competência estava discriminado nas competências da Diretoria de Planejamento Estratégico e Avaliação das Ações de Controle, a quem competia:

proceder ao registro, acompanhamento e controle das diligências, recomendações, julgamentos, notificações e demais comunicações processuais, oriundos do Tribunal 
de Contas da União, do Ministério Público ou de outros órgãos, que ensejem ações de controle da Secretaria Federal de Controle Interno (Brasil, 2003).

No decreto $n^{\circ} .5683$, de 24 de janeiro de 2006 (Brasil, 2006), sob a estrutura da SFC é possível identificar a Coordenação-Geral de Operações Especiais integrando a Diretoria de Planejamento e Avaliação das Ações de Controle. No escopo da coordenação constavam as atividades relacionadas ao Programa de Fiscalização a partir de Sorteios Públicos e o atendimento a representações e denúncias realizadas à CGU, por órgãos como Ministério Público, Tribunal de Contas da União (TCU) ou cidadãos. De forma ainda incipiente, constavam como atribuições da Diretoria de Planejamento "apoiar o Secretário Federal de Controle Interno na coordenação das ações de controle que exijam articulação centralizada com unidades regionais ou órgãos externos".

O Decreto n’. 8109 incluiu nas atribuições da SFC a de "planejar, coordenar, supervisionar e realizar auditorias e fiscalizações, e atuar em conjunto com outros órgãos na defesa do patrimônio público" (Brasil, 2013). Pela primeira vez, apareceu em normativos a identificação "órgãos na defesa do patrimônio público". A Coordenação-Geral de Operações Especiais permaneceu na estrutura da então renomeada Diretoria de Planejamento e Coordenação das Ações de Controle.

A Coordenação-Geral de Operações Especiais passou a compor a estrutura do gabinete da SFC na estrutura regimental definida pelo Decreto $n^{\circ}$. 8910, de 22 de novembro de 2016 (Brasil, 2016). Em 2019 a atividade de operações especiais é alçada ao nível de Diretoria de Operações Especiais (DOP) e passa a compor a estrutura da então criada Secretaria de Combate à Corrupção (SCC), que, além da DOP, tem em sua estrutura a nova Diretoria de Acordos de Leniência (DAL) e a antiga Diretoria de Pesquisas e Informações Estratégicas (DIE), anteriormente vinculada à Secretaria-Executiva da CGU.

Pelo atual decreto regimental, à SFC cabe então o papel de "apoiar, no âmbito de suas competências, as comissões de negociação de acordos de leniência e ações de operações especiais" (Brasil, 2019). À SCC cabe "propor ao Ministro de Estado a normatização, sistematização e padronização dos procedimentos e atos normativos que se refiram às atividades relacionadas a acordos de leniência, inteligência e operações especiais desenvolvidas pela CGU" (Brasil, 2019). As competências da DOP e suas coordenações-gerais passam a ser muito mais detalhadas. Dentre elas, "coordenar e orientar as unidades da CGU na prospecção de ações em parceria com as instituições de defesa do Estado", "instrumentalizar e padronizar os processos de trabalho inerentes às operações especiais", "articular, supervisionar, orientar, acompanhar e executar análises financeiras advindas de afastamento de sigilo bancário" e "supervisionar e monitorar as ações de controle de natureza investigativa e de operações especiais realizadas de forma integrada entre as CGU-R e em parceria com outros órgãos" (Brasil, 2019).

Conforme pode ser observado a partir da análise da Tabela 1, nos primeiros treze anos de exercício da CGU foram realizadas, em média, 15,30 operações especiais por ano, com um prejuízo potencial estimado de cerca de R\$ 21 milhões por ano. De 2016 a 2019, a média de operações realizadas ao ano subiu para 54,5 ao ano, com prejuízo potencial estimado de $\mathrm{R} \$ 47,5$ milhões ao ano. Com relação a 2020, foram realizadas 62 operações especiais até o início de outubro, onde foi contabilizado prejuízo potencial de $\mathrm{R} \$ 61,4$ milhões. Caso a frequência média mensal se mantenha até o final de 2020, haverá um crescimento de 36\% de operações especiais em relação à média anual do período de 2016 a 2019 e um crescimento de 300\% em relação ao período de 2003 a 2015.

Tabela 1: Quantidade de operações especiais realizadas pela CGU e potencial prejuízo

\begin{tabular}{ccc}
\hline Período & $\begin{array}{c}\text { Quantidade de operações } \\
\text { especiais }\end{array}$ & $\begin{array}{c}\text { Prejuízo potencial apurado } \\
\text { (em bilhões) }\end{array}$ \\
\hline 2003 a 2015 & 199 & $\mathrm{R} \$ 2,83$ \\
2016 a 2019 & 218 & $\mathrm{R} \$ 1,9$ \\
2020 (até início de outubro) & 62 & $\mathrm{R} \$ 0,06$ \\
\hline
\end{tabular}

Fonte: CGU (2020b, 2020c). 
Tabela 2: Quantidade de operações especiais realizadas pela CGU por área de política pública

\begin{tabular}{ccccc}
\hline Ano & $\begin{array}{c}\text { Quantidade } \\
\text { total de } \\
\text { operações }\end{array}$ & $\begin{array}{c}\text { Operações } \\
\text { em Saúde e } \\
\text { Educação }\end{array}$ & $\begin{array}{c}\text { Operações } \\
\text { em Esporte e } \\
\text { Cultura }\end{array}$ & $\begin{array}{c}\text { Operações } \\
\text { em outras } \\
\text { áreas de } \\
\text { políticas }\end{array}$ \\
\hline 2016 & 52 & 28 & 5 & 19 \\
2017 & 68 & 36 & 3 & 29 \\
2018 & 39 & 25 & - & 14 \\
2019 & 57 & 27 & - & 30 \\
\hline 2020 (até início de outubro) & 62 & $45^{*}$ & - & 17 \\
\hline
\end{tabular}

Fonte: CGU (2020b, 2020c). Nota: * 24 relacionadas à COVID-19

A maior parte das operações especiais foi realizada nas áreas de Saúde e Educação, como pode ser identificado pela Tabela 2. Em 2016, elas representam 53,8\% do total de operações realizadas. Em 2017, 52,9\%. Em 2018, 64,10\% e em 2019, 47,4\%. Em 2020, até o início de outubro, as operações especiais nas áreas de Saúde e Educação totalizaram 72,5\% do total, sendo $38,7 \%$ relacionadas a apuração de irregularidades em compras relacionadas ao COVID-19.

\section{Operações Especiais e Avaliação de Políticas Públicas}

Relevantes programas governamentais relacionados às áreas de Educação e da Saúde agrupam ações orçamentárias cujos recursos são descentralizados para os entes federativos para a execução das políticas públicas, tais como: Apoio à Alimentação Escolar na Educação Básica (PNAE), Dinheiro Direto na Escola para a Educação Básica (PDDE), Apoio ao Transporte Escolar na Educação Básica (PNATE), Aquisição de Veículos para o Transporte Escolar da Educação Básica - Caminho da Escola, Atenção Especializada à Saúde, Atenção Primária à Saúde, Segurança Alimentar e Nutricional e Assistência Farmacêutica no SUS (SIOP, 2020).

A efetividade dessas políticas depende fortemente da capacidade de implementação dos entes federativos, bem como da capacidade de coordenação e monitoramento realizada pelos ministérios setoriais. Nesse sentido, a clareza e adequação da estrutura de papeis dos envolvidos na política pública, a inserção de mecanismos controle, de prestação de contas e de transparência impacta a qualidade da sua execução.

Os principais problemas verificados pelas Operações Especiais na implementação de políticas públicas se relacionam a compras irregulares, apropriação de ativos de forma indevida e entregas de insumos de qualidade inferior ou em menor quantidade ao adquirido. Possíveis causas que possibilitam a ocorrência desses ilícitos se relacionam a falta de transparência, baixo nível de controle social e restrições à competitividade nas aquisições.

Atualmente os resultados das operações são divulgados na imprensa, com informações de acusados detidos e valores supostamente envolvidos. Desta forma o resultado dos trabalhos alimenta os processos penais, mas não tem impacto no processo de avaliação de políticas públicas.

A divulgação dos dados decorrentes das Operações Especiais no portal dados.gov.br informa: a) nome da Operação, b) área da política pública, b) prejuízo estimado, c) agentes públicos envolvidos nas fiscalizações, d) localidade, e e) questões judiciais, como sequestro de bens, mandado judicial, quebra de sigilo; mas o órgão detém informações mais robustas como, por exemplo, a situação constatada (empresas de fachada, fragilidades nos controles de legalidade de licitações etc.), que, caso sistematizadas por política pública, poderiam auxiliar na identificação de fragilidades no desenho ou na governança da política. 
Proposta de apropriação similar, mas a partir do Programa de Fiscalização por Sorteios Públicos, foi realizada por Paulo Januzzi (2011), quando defendeu a utilização dos relatórios de auditoria da CGU, elaborados a partir da realização das auditorias, para subsidiar a avaliação de programas públicos.

Por meio de Análise Estruturada de Textos (AET) aplicada sobre os relatórios de auditoria decorrentes de fiscalizações do Programa de Assistência Farmacêutica, em uma amostra de 597 municípios, o estudo revelou que

90,3\% deles apresentaram problemas na gestão de recursos ou serviços. Em $71 \%$ dos municípios foi constatada a falta de controle de estoque ou sua deficiência e em 39\%, condições inadequadas de armazenamento, identificando-se a falta desses produtos em $24 \%$ do total da amostra. (Januzzi, 2011, p.224).

A conclusão do estudo indicou a possibilidade de aproveitamento dos relatórios de fiscalização para identificação de deficiências de gestão dos programas na dimensão de "avaliação de processos de implementação de programas públicos"

No caso de nossa proposta, a sistematização de dados sobre as possíveis causas dos ilícitos verificados pelas Operações Especiais permitiria a identificação das principais falhas de integridade na gestão dessas políticas. Caso esse resultado fosse compartilhado com a SFC, poderia ser utilizado na avaliação do desenho e da governança das políticas públicas.

Segundo o Guia Ex-Post de Avaliações Públicas (Brasil, 2018), a avaliação do desenho verifica a consistência lógica do programa e de que forma insumos, processos, produtos, resultados e impactos são coordenados para a efetividade da política pública. O objetivo é verificar possíveis falhas e as necessidades de correção das etapas nas quais elas tiverem sido observadas. É possível observar incentivos adversos ou necessidade de adequação da focalização da política nesse tipo de avaliação. Considerando que mecanismos de controle devem ser previstos no desenho da política, de forma a minimizar os riscos de que os objetivos da política sejam alcançados, eles também deverão estar propostos no desenho da política pública. Mecanismos de accountability, enforcement, responsividade e transparência são alguns destes mecanismos, sendo o enforcement o que representa as possibilidades de sanção no caso de descumprimento do que foi acordado na regulamentação e nas regras da política, como desvio de finalidade ou não cumprimento da prestação de contas nos termos definidos. (Brasil, 2018)

Por outro lado, a avaliação da governança implica compreender de que forma "a implementação das políticas públicas está dotada de capacidades estatais adequadas ao nivel de complexidade dos problemas que pretende solucionar". Considerando as distintas esferas federativas envolvidas nas políticas públicas cujos recursos são descentralizados, este tipo de avaliação tem como objetivo principal "aprimorar a coordenação da execução da política pública, criando condições capazes de gerar e entregar resultados, de forma a melhor atender ao interesse público". (Brasil, 2018)

Nesse sentido, apesar de as Operações Especiais serem consideradas ações investigativas conjuntas realizadas por meio de parcerias com instituições federais que precedem a fase de persecução penal, tendo como principal enfoque a má aplicação na gestão dos recursos públicos federais (CGU, 2020b; Straus, 2020), identificamos forte potencial de utilização dos resultados de suas ações como subsídio tanto para avaliações de desenho quanto para avaliações de governança, quer elas sejam realizadas pelos órgãos centrais ou pelos próprios ministérios setoriais responsáveis pelas políticas.

Podemos observar com relação ao número de operações realizadas, que, desde o início dessa atividade, a maior parte refere-se a recursos públicos federais destinados às áreas de Educação e Saúde, ministérios que envolvem grande parte de recursos públicos registrados no orçamento federal. Argumentamos que os insumos derivados dessa atividade seriam de grande relevância para o aprimoramento dessas políticas públicas.

Ao serem analisadas as causas que possibilitaram as fraudes verificadas nas atividades de operações especiais, de forma consolidada, seria possível subsidiar os ministérios setoriais no sentido de propor novas regulamentações para a política, novo desenho do programa e até mesmo controles mais adequados, que minimizariam o risco de fraudes. 
Estudos ainda iniciais realizados sobre a efetividade das Operações Especiais indicam sua incipiência no combate à corrupção, dado que a morosidade para se encerrar o ciclo dos trabalhos, englobando ações administrativas, cíveis e penais é bastante alta, implicando em prejuízo relevante na aplicação de efetivas punições aos responsáveis pelos delitos (Straus, 2020).

Segundo o Ministro da CGU, Wagner Rosário, das operações especiais realizadas em 2020, 29 tiveram iniciativa na própria CGU (Agência Brasil, 2020). Isso significa dizer que decorreram de auditorias realizadas pelo próprio órgão, quer seja no âmbito do Programa de Fiscalização em Entes Federativos, quer seja por meio de avaliações realizadas pela SFC.

Essa afirmação reforça nosso argumento de que a identificação das fragilidades encontradas no desenho e na governança das políticas públicas que favoreceram o cometimento dos delitos apurados por meio de Operações Especiais está sob a governança do próprio Poder Executivo, que pode se utilizar desses insumos para contribuir com o aumento da efetividade das políticas públicas.

\section{Considerações Finais}

Ao analisarmos os normativos e os decretos de estrutura das atividades da CGU, é possível observar, além da mudança de status da atividade de operações especiais, a mudança de foco. Ao início, a Coordenação-Geral de Operações Especiais abarcava a atividade de Fiscalização por Sorteios Públicos, que, conforme pesquisas acadêmicas, tinha forte viés de prevenção à corrupção (Ferraz \& Finan, 2008; Pizzolato, 2012; Santana, 2008).

Com o passar do tempo, a atividade de operações especiais foi se descolando do viés de prevenção e passou a se identificar diretamente com as ações de combate à corrupção, vínculo aprofundado com a sua inserção na estrutura da recém criada Secretaria de Combate à Corrupção.

Apesar dessa mudança, o argumento deste ensaio é de que o resultado das Operações Especiais, que são atividades realizadas para apurar recursos federais indevidamente aplicados em políticas públicas, podem contribuir de maneira mais expressiva para a avaliação de políticas públicas, especialmente as avaliações de desenho e de governança.

São diversos os desafios para essa apropriação. A mudança de estrutura que transferiu as atribuições das Operações Especiais para a Secretaria de Combate à Corrupção é uma delas. Considerando que a competência de avaliar as políticas públicas permanece na Secretaria Federal de Controle Interno, a retroalimentação do processo exigiria uma maior interface entre as duas Secretarias, com criação de fluxos para compartilhamento de resultados (Brasil, 2017).

Outro desafio é o detalhamento de competências inserido no novo decreto regimental da CGU, quanto às ações da Diretoria de Operações Especiais. A especialização cada vez maior da área responsável por essas atividades pode fazer com que ela se volte cada vez mais para as relações interinstitucionais, em detrimento das interorganizacionais. As competências de "coordenar e orientar as unidades da CGU na prospecção de ações em parceria com as instituições de defesa do Estado" e "supervisionar e monitorar as ações de controle de natureza investigativa e de operações especiais realizadas de forma integrada entre as CGU-R e em parceria com outros órgãos" (Brasil, 2019) parecem confirmar essa hipótese.

Apesar disso, o regimento contempla a competência de "instrumentalizar e padronizar os processos de trabalho inerentes às operações especiais" (Brasil, 2019). É possível, portanto, pensar em inserir etapas de interlocução com as áreas responsáveis na CGU pelas avaliações de políticas e de criação de fluxo procedimental, que registre de forma sistematizada os resultados das operações, programas fiscalizados e possíveis causas de quebra de integridade, contribuindo, assim, para o debate sobre que normativos, estruturas ou competências institucionais devem ser desenvolvidos para que as fraudes ora detectadas sejam mais difíceis de serem impetradas, proporcionando, assim, maior efetividade das políticas públicas. 


\section{Fonte de financiamento}

Não há.

\section{Conflito de interesse}

Não há.

\section{Agradecimentos}

Agradeço ao Prof. Dr. Francisco Gaetani, meu orientador no Mestrado, que continuamente nos instiga a produzir textos que possam contribuir com a melhoria da gestão pública.

\section{Referências}

Agência Brasil. (2020, Outubro 15). Operações conjuntas entre PF e CGU apontam prejuízos de R\$1,1bi. Isto É. Recuperado em 17 de outubro de 2020, de https://www.istoedinheiro.com.br/operacoes-conjuntasentre-pf-e-cgu-apontam-prejuizos-de-r-11-bi/

Brasil. Constituição Federal. (1988). Artigo 74 da Constituição Federal de 1988. Recuperado em 16 de outubro de 2020, de https://www.senado.leg.br/atividade/const/con1988/con1988_07.05.2020/art_74_.asp

Brasil. (2018). Casa Civil da Presidência da República, Ministério da Transparência e Controladoria-Geral da União, Ministério da Fazenda, Ministério do Planejamento, Desenvolvimento e Gestão, Instituto de Pesquisa Econômica Aplicada. Avaliação de políticas públicas: guia prático de análise ex post. Brasília, DF: Casa Civil da Presidência da República. Recuperado em 16 de outubro de 2020, de https://www.ipea.gov. br/portal/images/stories/PDFs/livros/livros/181218_avaliacao_de_politicas_publicas_vol2_guia_expost.pdf

Brasil. (2002, novembro 28). Aprova a Estrutura Regimental e o Quadro Demonstrativo dos Cargos em Comissão e das Funções Gratificadas da Corregedoria-Geral da União, e dá outras providências (Decreto $n^{\circ}$ 4.490, de 28 de novembro de 2002). Diário Oficial [da] República Federativa do Brasil, Brasília. Recuperado em 18 de outubro de 2020, de http://www.planalto.gov.br/ccivil_03/decreto/2002/D4490.htm

Brasil. (2003, julho 21). Aprova a Estrutura Regimental e o Quadro Demonstrativo dos Cargos em Comissão e das Funções Gratificadas da Controladoria-Geral da União, e dá outras providências (Decreto $n^{\circ} 4.785$, de 21 de julho de 2003). Diário Oficial [da] República Federativa do Brasil, Brasília. Recuperado em 18 de outubro de 2020, de http://www.planalto.gov.br/ccivil_03/decreto/2003/D4785.htm

Brasil. (2006, janeiro de 24). Aprova a Estrutura Regimental e o Quadro Demonstrativo dos Cargos em Comissão e das Funções Gratificadas da Controladoria-Geral da União, e dá outras providências (Decreto $n^{\circ}$ 5.683, de 24 de janeiro de 2006). Diário Oficial [da] República Federativa do Brasil, Brasília. Recuperado em 18 de outubro de 2020, de http://www.planalto.gov.br/ccivil_03/_Ato2004-2006/2006/Decreto/D5683.htm

Brasil. (2013, setembro de 17). Aprova a Estrutura Regimental e o Quadro Demonstrativo dos Cargos em Comissão e das Funções Gratificadas da Controladoria-Geral da União, e remaneja caros em comissão (Decreto n 8.109, de 17 de setembro de 2013). Diário Oficial [da] República Federativa do Brasil, Brasília. Recuperado em 18 de outubro de 2020, de http://www.planalto.gov.br/ccivil_03/_ato2011-2014/2013/ decreto/D8109.htm\#: :text=Aprova\%20a\%20Estrutura\%20Regimental\%20e,e\%20remaneja\%20 cargos\%20em\%20comiss\%C3\%A3o

Brasil. (2016, novembro de 22). Aprova a Estrutura Regimental e o Quadro Demonstrativo dos Cargos em Comissão e das Funções Gratificadas do Ministério da Transparência, Fiscalização e ControladoriaGeral da União, remaneja caros em comissão do Grupo Direção e Assessoramento Superiores - DAS por Funcções Comissionadas do Poder Executivo - FCPE (Decreto n 8.910, de 22 de novembro de 2016). Diário Oficial [da] República Federativa do Brasil, Brasília. Recuperado em 18 de outubro de 2020, de http:// www.planalto.gov.br/ccivil_03/_ato2015-2018/2016/decreto/D8910.htm

Brasil. (2019, janeiro de 03). Aprova a Estrutura Regimental e o Quadro Demonstrativo dos Cargos em Comissão e das Funções de Confiança da Controladoria-Geral da União, remaneja cargos em comissão e funções de confiança e substitui cargos em comissão do Grupo-Direção e Assessoramento Superiores DAS por Funções Comissionadas do Poder Executivo - FCPE. (Decreto n 9.681, de 3 de janeiro de 2019). Diário Oficial [da] República Federativa do Brasil, Brasília. Recuperado em 18 de outubro de 2020, de http:// www.planalto.gov.br/ccivil_03/_Ato2019-2022/2019/Decreto/D9681.htm

Brasil. (2001, fevereiro de 06). Organiza e disciplina os Sistemas de Planejamento e de Orçamento Federal de Administração Financeira Federal, de Contabilidade Federal e de Controle Interno do Poder Executivo Federal, e dá outras providências. (Lei n 10.180, de 06 de fevereiro de 2001.). Diário Oficial [da] República Federativa do Brasil, Brasília. Recuperado em 18 de outubro de 2020, de http://www.planalto.gov.br/ ccivil_03/leis/leis_2001/l10180.htm

Sistema Integrado de Planejamento e Orçamento - SIOP. (2020). Recuperado em 16 de outubro de 2020, de http://www1.siop.planejamento.gov.br/acessopublico/?pp=acessopublico\&ex=0\&fp=inicio

Brasil. Ministério da Transparência. Controladoria-Geral da União - CGU. (2017, junho 09). Aprova o Referencial Técnico da Atividade de Auditoria Interna Governamental do Poder Executivo Federal (Instrução 
Normativa CGU n 03/2017). Diário Oficial [da] República Federativa do Brasil, Brasília. Recuperado em 15 de outubro de 2020, de https://repositorio.cgu.gov.br/bitstream/1/33409/11/Instrucao_Normativa CGU_3_2017.pdf

Controladoria-Geral da União - CGU. (2020a). Programa de Fiscalização em Entes Federativos. Recuperado em 15 de outubro de 2020, de https://www.gov.br/cgu/pt-br/assuntos/auditoria-e-fiscalizacao/programade-fiscalizacao-em-entes-federativos

Controladoria-Geral da União - CGU. (2020b). Operações Especiais. Recuperado em 15 de outubro de 2020, de https://www.gov.br/cgu/pt-br/assuntos/operacoes-especiais

Controladoria-Geral da União - CGU. (2020c). Operações especiais. Anos anteriores. Recuperado em 15 de outubro de 2020, de https://www.gov.br/cgu/pt-br/assuntos/operacoes-especiais/anos-anteriores

Ferraz, Claudio, \& Finan, Frederico. (2008). Exposing corrupt politicians: The effects od Brazil's publicy released audits on electoral outcomes. The Quarterly Journal of Economics, 123(2), 703-745. http://dx.doi. org/10.1162/qjec.2008.123.2.703

Januzzi, Paulo. (2011) Avaliação de Programas Públicos por meio da Análise Estruturada dos Relatórios de Auditoria da Controladoria-Geral da União. Cadernos de Gestão Pública e Cidadania, 16(59), 222-239.

Loureiro, Maria Rita, Abrucio, Fernando Luiz, Olivieri, Cecília, \& Teixeira, Marco Antonio Carvalho. (2012). Do Controle Interno ao Controle Social: A múltipla atuação da CGU na democracia brasileira. Cadernos Gestão Pública e Cidadania, 17(60), 54-67.

Pizzolato, Bruna (2012). O Papel da Controladoria Geral da União como mecanismo de Controle Interno. Temas de Administração Pública, 4(7), 1-17.

Rosário, Wagner Campos, Da Silva, Fabio do Valle Valgas, Fattori, Danusa da Matta Duarte, \& Neves, Otávio Moreira de Castro. (2020, Novembro). Controle interno para a boa governança pública. Anais do XXV Congreso Internacional del CLAD sobre la Reforma del Estado y de la Administración Pública. (pp. 24-27). Lisboa. Portugal.

Santana, Victor Leal. (2008). O impacto das auditorias da CGU sobre o desempenho administrativo local. Revista da CGU, 3(5), 22-27.

Secretaria Federal de Controle Interno - SFC (2001, abril 10) Define diretrizes, princípios, conceitos e aprova normas técnicas para a atuação do Sistema de Controle Interno do Poder Executivo Federal (Instrução Normativa SFC n01/2001). Diário Oficial [da] República Federativa do Brasil, Brasília. Recuperado em 15 de outubro de 2020, de https://www.normasbrasil.com.br/norma/?id=74573 Acesso em 18/10/2020

Sodré, Flavius \& Ramos, Francisco. (2018, julho). Corrupção e Pobreza: Evidências a Partir do Programa de Fiscalização Por Sorteios Públicos da CGU. Anais da ANPEC - 12 Economia Social e Demografia Econômica.

Straus, Henrique. (2020). A efetividade das Operações Especiais realizadas em MT no período de 2014 e 2015 com a participação conjunta da CGUMT, Polícia Federal e Ministério Público Federal. (Dissertação). Universidade Federal de Lavras, Lavras. 